\title{
Improving the efficiency of Port Community Systems through integrated information flows of logistic processes
}

Marco Bisogno. University of Salerno. Italy. mbisogno@ unisa.it

Giancarlo Nota. University of Salerno. Italy. nota@unisa.it

Antonello Saccomanno. University of Salerno. Italy. asaccomanno@unisa.it

Aurelio Tommasetti. University of Salerno. Italy. tommasetti@unisa.it

\begin{abstract}
The aim of the paper is to investigate maritime logistic processes, focusing on efficiency and coordination. The topic is timely because, in the European context, the EU Directive no. 2010/65/EU imposes the adoption of digital procedures concerning documents and information, in order to facilitate the relationships between all the actors of a port community system (PCS). From a theoretical viewpoint, we adopt the evolutionary economic approach, since it helps to understand the change processes due to its focus on organizational routines and their institutionalization. From a methodological viewpoint, we adopt a case-study approach, investigating the port of Salerno (south of Italy), which is involved in the "Smart Tunnel Project", whose aim is to create a platform for intelligent logistic services. As a result, we provide a model that aims to replace the old interorganizational routines with new more efficient ones, also improving the knowledge of the logistic processes through a facilitation of the exchange of documents and information between all the involved actors.
\end{abstract}

Keywords: port; port community system; coordination; efficiency; routines; case study.

\section{INTRODUCTION}

Current literature considers ports as complex networks which require a better integration among all the actors involved in the global supply chain (Bagchi and 
Paik, 2001; Baron and Mathieu, 2013; van Baalen and Zuidwijk, 2008). The coordination between local partners of such a network (port community system, hereafter PCS) plays a crucial role in supporting the competitiveness and efficiency of the port itself (and vice versa), with a reduction in both the costs and the time needed to pass through the port.

The relationships between the partners of a PCS consist of physical, financial and information flows. We focus on the information flows not only because of their crucial relevance in supporting planning, execution, managing and reporting in container handling (van Oosterhout, 2008), but also because of a recent EU Directive no. 2010/65/EU, which will impose (from August 2015) the adoption of digital procedures concerning documents and information.

The aim of the paper is to investigate inter-organizational routines characterizing PCSs providing a model of an integrated information system, able to take into account the entire information requirements of all the actors in the supply chain.

From a theoretical viewpoint, we refer to the evolutionary economic approach (Nelson and Winter, 1982), which is particularly appropriate in this context since it focuses on organizational routines and their institutionalization. Therefore, this approach helps to understand the change processes (Burns and Scapens, 2000) required by the introduction of thorough technological innovations within interorganizational information system.

From a methodological point of view, we adopt a case study approach, investigating the port of Salerno, situated in the south of Italy, whose volume of traffic has grown over recent years. This urban port is involved in the "Smart Tunnel Project" (see Section 5), which aims to create a platform for intelligent logistic services in order to maximize its efficiency. Through semi-structured interviews with local actors of the PCS of Salerno as well as periodic meetings with the partners of the Smart Tunnel Project, we investigated inter-organizational routines needed to pass through the port and the ICT systems/methods of communication implemented.

As a result, we provide a model based on the Business Process Modelling Notation, together with a top down method for the design and the realization of 
communication flows in logistic processes. The implemented prototype adopted the Business Process Execution Language (BPEL) and XML technology, improving the knowledge of the logistic processes and facilitating the exchange of documents and information between all partners.

The remainder of the paper is structured as follows. The second section reviews the literature while the third one summarizes the characteristics of our case study. The fourth section provides a meta-model for logistic communications in the light of the main issues of the Smart Tunnel Project illustrated in the fifth section. Finally, the last section presents several conclusions as well as future developments of the study.

\section{LITERATURE REVIEW}

According to the European Port Community Systems Association (EPCSA, 2011), a PCS is an open electronic platform that connects the multiple systems operated by different seaport organisations (Rodon and Ramis-Pujol, 2006). It enables intelligent and secure exchange of information between both private and public organizations, with the main aim being to improve the competitiveness of the port. From this perspective, an efficient collaboration between all the involved organizations is the essential prerequisite to optimise all the logistic processes through a single data submission (Long, 2009).

PCSs in Europe have a long tradition; the first experiences (i.e. the first PCS generation; Moonen and Srour, 2008) began to operate in the late 70s or early 80s in Germany, France and the UK, followed in the 90s by other countries such as the Netherlands and Spain. In fact, it was then clear that the increased growth in international sea trade caused a series of issues related to administrative processes and documents, which could not be solved through a mere expansion of the port: a faster movement of goods required a faster authorization and clearance procedures, so paper documents had to be substituted by electronic communications. Therefore, these PCSs not only improved the coordination of all goods transferral between all the involved stakeholders but also the controlling activities on the part of the Customs and other port authorities.

Previous studies investigating PCSs focused on private and public partnerships between the port stakeholders (Bagchi and Paik, 2001), on the collective work 
achieved by the port community or on the adoption process (Rodon and RamisPujol, 2006) as well as on the architecture of the information system (van Baalen et al., 2008). More recently, Baron and Mathieu (2013) have analysed PCS interoperation at the European level, highlighting how PCS operators are now prominent actors in the maritime transport activity. In this vein, PCS usually includes ship owners, handlers, road or rail carriers, warehouse owners, as well as forwarding agents or commissioners (i.e. trading partners); moreover, the PCS typically includes different governmental organizations, such as port authorities, customs, coastguards and veterinary offices.

According to these studies, a PCS requires a strong relationship between the customs and other public as well as private organizations. In fact, the information flows from these different stakeholders through all the phases, starting from the steps preceding the arrival of goods to the final processes of transporting them out of the port.

Along this line, Baron and Mathieu (2013) point out that the key success factor of a PCS is a good collaboration between all the involved public (especially the Customs) and private parties, demonstrated through an analogy between the PCS industry and the card payment industry, as well as with interviews with both PCS stakeholders (handler and carrier, ship owner, sea freight forwarder) and employees and managers of PCS operators. Scholars provide an interesting analysis of the market organization, the types of rules to take into consideration, the architecture of the system as well as some of the constraints, which still remain in building a European market for maritime information.

Their main conclusion is that full interoperability between all the involved partners would facilitate transactions for the larger European players and promote greater competition among PCS operators.

Following this line, we propose a different methodological approach based on a more detailed (i.e. microeconomic) level of analysis. Starting from the basic notion that a standardized communication platform is the principal constituent of a PCS, we sustain that an in depth understanding of port logistics could be the right path to follow in order to improve their reliability and efficiency. The central position of the port within a network of local players, among which a full 
interoperability should exist, requires an approach based on a thorough understanding of the organizational routines of each partner as well as the interorganizational routines which characterise the relationships between them.

From this perspective, a PCS can be considered a carrier of specific sets of routines that have a collective nature, because they involve different actors; while habits and skills refer to individuals, routines concern groups, representing the components of institutions. According to Becker (2004), routines provide some degree of stability as well as a contrast required to detect novelty, i.e. to make it possible to map organizational change. Routines are triggered by the actions of individuals and/or by external cues. They can change over time because of the competition between ports and among organizations within each port as well as because of technological innovations. In addition, routines can change because national as well as international laws and regulations can introduce incisive innovations.

In our case, one of the main external triggers is the recent EU Directive no. 2010/65/EU, that will impose (from August, 2015) the adoption of digital procedures concerning documents and information; the aim is to facilitate the relationships between shipping companies, terminal, the Customs and the control authorities as well as the relationship with the dry port and/or logistic platform.

Obviously, the strong competition between the private actors of each port needs to be balanced with a cooperative view, considering the above-mentioned EU Directive as a favourable occasion for selecting the organizational culture, maintaining the appropriate routines and eliminating the out-dated ones.

From this point of view, rules and routines, which have been effective in the past, can be considered as the basis of individual actions, because they have been institutionalized (Scapens, 1994). The uncertainty and complexity concerning the future can be managed by adopting a rule-based behaviour; as a consequence, rules and routines can be considered the organizational counterpart of individual habits and skills, providing a potential source of resistance to change ${ }^{1}$.

\footnotetext{
${ }^{1}$ A routine is a "pattern of behaviour that is followed repeatedly but which is subject to change if conditions change" (Winter, 1964). Therefore, while rules represent a formalized set of procedures, routines denote the procedures actually in use, and which represent the "way of doing things" (Nelson and Winter, 1982; Burns and Scapens, 2000). As a
} 
From both a theoretical and methodological viewpoint, the choice of studying "if" and "how" inter-organizational routines of a PCS change over time under the pressure of external cues leads to some relevant implications.

Firstly, our research is founded on the old institutional economics (OIE) approach, because we aim at studying the process of change (and not the outcome of the change), requiring a conceptualization of the ways in which new routines evolve over time (Nelson and Winter, 1982).

Secondly, we start from the criticism sustained by Scholars regarding the way institutional theory has been adopted in exploring "how" organizations respond to pressures from the institutional environment; in fact, this approach, among other aspects, fails to recognise the processes through which institutions are created, adapted, transposed and/or discarded (Dacin et al., 2002; Scott, 2001; Seo and Creed, 2002) as well as to be aware of power and interest at the organizational level (Scott 2001; Dillard et al., 2004; Lounsbury, 2007). Consequently, through the lens of the OIE, we aim to provide a greater understanding of processes of change $^{2}$, in order to improve the reciprocal coordination characterizing logistic processes involving the stakeholders of a PCS.

As we better explain in the next section, we will adopt a top down approach, moving from a meta-level of investigation concerning the key phases of the whole export process in international trade; in the second step, we provide an in depth analysis of some of these key processes, taking into account that the underlying diagrammatic logical can be easily applied to other processes. Therefore, we will try to understand the change processes by investigating inter-organizational routines in accordance with the well-known three-stage model of organizational innovation proposed by Thompson (1965):

1. The generation of an innovative idea or proposal;

consequence, routines provide an organizational memory that resists change, representing the basis of the concept of stability. This does not mean that there is a necessary and logical connection between past actions and present behaviour, because organizations evolve over time (e.g. administrative practices are highly institutionalized but they change over time).

${ }^{2}$ See Modell and Wiesel (2008: 255), who calls for "a deeper understanding of why practice variations embedded in competing institutional logics emerge within an institutional field". 
2. The acceptance of an innovation, which implies more or less insightful changes in organizational as well inter-organizational routines;

3. The implementation of the innovation so that it becomes ingrained within the organizational and inter-organizational behaviour.

Innovation literature widely considers this model to be the most representative and conceptually straightforward of the innovation models (Damanpour and Schneider, 2006; Kwon and Zmud 1987; Pierce and Delbecq, 1977; Swanson, 1994; Zmud, 1982); even though some of these studies have identified other stages, in order to gain a better interpretation of the innovation processes, they can be easily mapped onto Thompson's original three stages (Bunduchi and Smart, 2010), to which we refer. Accordingly, we implicitly consider both the benefits (more specifically: direct, indirect and strategic benefits; Chwelos et al., 2001; Iacovou et al., 1995; Jimenez-Martinez and Polo-Redondo, 2004; Weber and Kantamneni, 2002) and the costs of innovation processes, more specifically: relational costs (Allen et al., 2000; Hart and Saunders, 1998; Nakayama, 2000), development costs (Antonelli, 1994; Gupta et al., 2008), implementation costs (Irani and Love, 2000; 2001) and switching costs (Zhu et al., 2006).

According to this theoretical background, we adopt a case study approach (Yin, 1994), providing empirical descriptions of the logistic processes of the port of Salerno (situated in the south of Italy) and emphasizing the rich, real-world context in which the phenomena occur (Eisenhardt and Graebner, 2007). As we will better explain in the fourth section, not sufficient care has been given to the design of an integrated information system capable of taking into account the entire information requirements of each organization of the whole supply chain. As such - and taking into account that there is a transition from the first to the second generation of PCSs (Moonen and Srour, 2008; van Oosterhout et al., 2008) - our phenomenon-driven research questions concern "how" an integration could be pursued, in what way it could affect existing routines and "why" actors of a PCS resist to change (see Edmondson and McManus, 2007, about the appropriateness of a case study approach when the researcher addresses "how" and "why" research questions). 


\section{THE CASE STUDY: THE PCS OF SALERNO}

The port of Salerno is a transhipment port in southern Italy, which handled 263.406 teus in 2013. As Table 1 shows, in the last five years, commerce has increased by $5.8 \%$ in terms of the number of ships and by $10.3 \%$ in terms of the gross tonnage of ships.

\begin{tabular}{|l|c|c|c|c|r|r|r|r|r|r|r|}
\hline \multicolumn{10}{|c|}{ Commercial Traffic } \\
\hline \multicolumn{2}{|c|}{} & $\mathbf{2 0 0 9}$ & \multicolumn{2}{|c|}{$\mathbf{2 0 1 0}$} & \multicolumn{2}{|c|}{$\mathbf{2 0 1 1}$} & \multicolumn{2}{|c|}{$\mathbf{2 0 1 2}$} & \multicolumn{2}{|c|}{$\mathbf{2 0 1 3}$} & \\
\hline \multicolumn{2}{|c|}{$n / t$} & \multicolumn{1}{|c|}{$n / t$} & var $\%$ & \multicolumn{1}{|c|}{$n / t$} & var $\%$ & $n / t$ & var $\%$ & $n / t$ & var \% & cagr $^{3}$ \\
\hline Ships in port & $(n)$ & 2.063 & 2.178 & $5,6 \%$ & 2.531 & $16,2 \%$ & 2.543 & $0,5 \%$ & 2.584 & $1,6 \%$ & $5,8 \%$ \\
\hline Gross tonnage of ships & $(t / 000)$ & 45.515 & 50.739 & $11,5 \%$ & 59.367 & $17,0 \%$ & 61.484 & $3,6 \%$ & 67.317 & $9,5 \%$ & $10,3 \%$ \\
\hline
\end{tabular}

Table 1: Commercial traffic in port of Salerno 2009- 2013

In recent years, due to the technological upgrading concerning the equipment for the handling of goods, several lines of regular container ships to and from different countries (Australia, New Zealand, the Far East, North Europe, Central, North and South America, West Africa) have been established. Since 2001, the Port of Salerno has been included into the new system of maritime transport of Short Sea Shipping named "Motorways of the Sea", a major project that aims to develop a modal shift from road to sea, as envisaged in the National Plan of logistics and approved by both the Council and the European Parliament in the framework of the TEN-T (Trans European Network-Transport).

The port of Salerno is an interesting case study due to the following characteristics:

- As a transhipment port, it is an important hub with ports of Europe, Africa, America and Asia and the shipping companies influence its strategic choices, because they may change their routes in order to minimize the average cost per unit transported. As a consequence, timing and efficiency play a crucial role in sustaining and incrementing the competitiveness of the port of Salerno;

- As an urban port, the relationship with the local environment and its viability affects its strategic choices. The urban infrastructures serving the port of Salerno are lacking in facilities as well as railway sidings. The proximity to the city and the geographical location of the area in which it stands prevents the

${ }^{3}$ Compound annual growth rate. 
growth of trade and the physical development of the port itself. Moreover, its proximity has a negative impact on the local traffic, emphasizing the importance of the relationship with the retro-port. The carriers are trying to reduce operating time by optimizing the flow of merchandises in order to reduce negative impact of these problems; nevertheless, the export times are still too high, due to bureaucratic and administrative procedures.

In fact, the timing involved in exporting is one of the vital elements for the functional competitiveness of a port. For this reason, the Italian government has financed the "Smart Tunnel" project (see: http://goo.gl/0Fgfbc), which involves the installation of a PCS for an innovative supply chain management in order to reduce the bureaucracy on the storage time of goods within the port. The project aims to create a platform for intelligent logistic services for urban ports, in order to maximize the security and efficiency of ports as well as the electronic control of material and immaterial flows of urban freight distribution chains. The project also aims to remove the inefficiencies of the bureaucratic interconnections, improving the level of efficiency and sustainability of the transport of goods in urban areas.

On that purpose, public organizations have implemented electronic platforms, with the main aim being to improve the coordination between PCS's operators thereby removing some inefficiency. For example, the Customs implemented a platform for electronic filing practices, named $\mathrm{AIDA}^{4}$; in the same way, the Coastguard enacted the Port Management Information System (PMIS), used by the Coastguard itself both in the execution of administrative procedures related to the arrival and departure of ships as well as for the supervision of the circulation around the port. Unfortunately, the AIDA system, on one hand, requires a manual entry of the data; on the other, it does not interact with the information systems of private organizations. Similarly, the PMIS is not "user friendly" and, like the AIDA system, it is not perfectly compatible with the legacy systems of the operators in the maritime transport chain.

\footnotetext{
${ }^{4}$ AIDA is the information system of the Customs, which sustains the electronic customs clearance of goods and allows communication with the operators and firms, the Government and the EU countries. Its approach is based on single windows/one stop shop.
} 


\section{A META-MODEL FOR LOGISTIC COMMUNICATIONS}

Any healthy organization or network of organizations, which aims towards the achievement of certain goals, can greatly benefit from the support of an efficient and effective communication system.

We apply this general concept to the logistic management realm, defined as "The process of planning, implementing, and controlling the efficient, effective flow and storage of goods, services, and related information from point of origin to point of consumption for the purpose of conforming to customer requirements" (Brook, 1993). As a consequence, it should be clear the importance of an effective and efficient communication system. Communication, in fact, permeates the whole logistic life cycle, starting from the planning of flow and storage of goods, through the monitoring and control of the logistic processes along the supply chain and concluding with the delivery of the goods to the customer. Communication involves different stakeholders of the supply chain, requiring substantial time to sustain the needs of different kinds of logistic processes. Rapid and effective communication allows competitive advantages for firms that offer and receive logistic services: as pointed out by Asbjørnslett et al. (2012), the efficiency of supply chain management is fully dependent on the quality and timeliness of the data available in the communication systems.

Recent initiatives, either concerning specific norms (see, for example, the above-mentioned EU Directive 2010/65/EU) or concerning the design of various kinds of single window systems (UN/CEFACT, 2005, UN/CEFACT, 2014; WCO, 2009), give input for the implementation of a new generation information system; however, the harmonization of the communication that supports the supply chain is still far from being achieved. Information systems are usually developed by organizations for their proper functions and very little attention is given to the design of a uniform and unified communication system that is able to cover the whole information needs of the supply chain. Indeed, the enabling technology is mature to build new capable software applications; for example, Workflow Management Systems and Enterprise Service Bus allow, respectively, the interoperability of business processes and the integration of legacy systems. However, their potential is not fully exploited due to the lack of reference models and analysis. 
The model proposed in this section develops the analysis phase (shown in grey in Figure 1) of the general methodology presented in IMO (2011) for the setting up a single window system in maritime transport. We aim to provide a model, a method and some guidelines for the implementation of a communication system that covers the whole supply chain.

The analysis phase mentioned above is here qualified by characterizing the usual AS-IS, TO-BE and GAP Analysis:

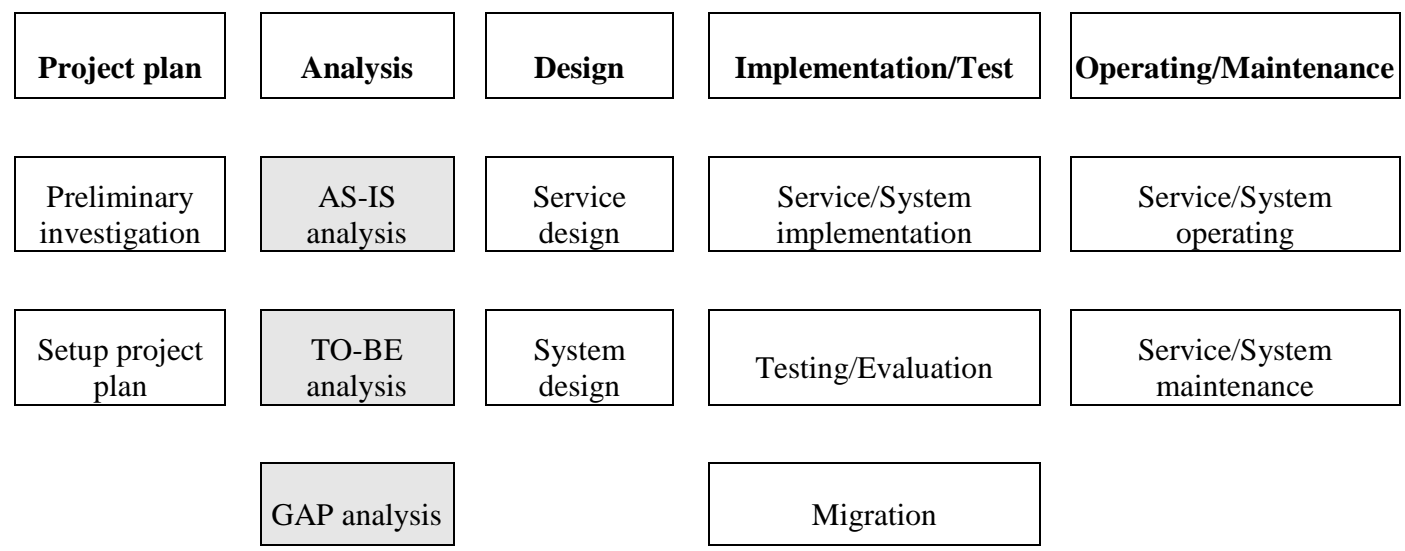

Figure 1: General methodology for normal system implementation

a) AS-IS Analysis: interview with stakeholders, abstract view of the top level process leading the supply chain, definition of collaboration diagrams among stakeholders, refinement of top level sub-processes, identification of exchanged documents for the freight management.

b) TO-BE Analysis: analysis of exchanged documents, identification of common data and information exchanged by processes enacted during the supply chain, reengineering of business processes, XML coding of documents, architecture of an ICT system for the support of communication needs.

c) GAP analysis: comparison of the actual process performance with the potential process performance, definition of a transition plan from the ASIS to the TO-BE scenario in terms of transition activity from the old process to the new one, migration and management costs, expected benefits and learning needs. 
We describe the two steps of our analysis model through a case study concerning administrative activities during an export process in the context of international trade and transport. The case study is described as a top down development and focuses on a first step regarding the AS-IS scenario and a further step, regarding the TO-BE analysis.

\subsection{AS IS Analysis}

The AS-IS analysis was based on semi-structured interviews with the actors of the PCS of Salerno, as Table 2 shows.

We also collected empirical data through periodic meetings with the partners of the "Smart Tunnel" project (see Section 5): a shipping company, a software house and a logistic firm, as well as with researchers of three departments (Management \& Information Technology; Computer science; Engineering) of the University of Salerno involved in the project. We had four general meetings with all the partners and about twenty meetings with some of them.

\begin{tabular}{|c|c|c|c|}
\hline Organizations & $\begin{array}{l}\text { Respondents } \\
\text { function }\end{array}$ & Duration & Topics \\
\hline Customs & $\begin{array}{l}\text { Customs Office } \\
\text { Director } \\
\text { Customs } \\
\text { Inspector }\end{array}$ & $\begin{array}{l}\text { About } 3 \\
\text { hours }\end{array}$ & $\begin{array}{l}\text { Administrative procedures related to Customs } \\
\text { declaration, AIDA system, control procedures, } \\
\text { process of export and fiscal documents for } \\
\text { shipping. }\end{array}$ \\
\hline \multirow{3}{*}{$\begin{array}{l}\text { Maritime agency } \\
\text { ("Michele Autuori } \\
\text { s.r.l.") }\end{array}$} & CEO & $\begin{array}{l}\text { About } 8 \\
\text { hours }\end{array}$ & \multirow{3}{*}{$\begin{array}{l}\text { Organization and characteristics of the port of } \\
\text { Salerno, software management cargo ship, } \\
\text { mooring plans, cargo manifest and bill of } \\
\text { landing, information flow, administrative } \\
\text { documents }\end{array}$} \\
\hline & $\begin{array}{l}\text { Assigned to } \\
\text { managing of } \\
\text { the cargo ship }\end{array}$ & About 2 & \\
\hline & $\begin{array}{l}\text { Assigned to } \\
\text { practices vessel }\end{array}$ & & \\
\hline $\begin{array}{l}\text { Sea freight forwarder } \\
\text { agent ("D'Angiolo") }\end{array}$ & $\begin{array}{l}\text { Forwarder } \\
\text { agent }\end{array}$ & $\begin{array}{l}\text { About } 4 \\
\text { hours }\end{array}$ & $\begin{array}{l}\text { Process of export, process of negotiation, } \\
\text { business procedures related to Customs } \\
\text { declaration. }\end{array}$ \\
\hline
\end{tabular}

Table 2: Interviews with operators in the port of Salerno

The analysis focuses on the export process, from which deepens the logical flow of information in organizational and inter-organizational routines, from the negotiation to the loading of the goods on the ship. 
Figure 2 shows the top level Business Process Modelling Notation (BPMN) diagram driving the whole export process in international trade. The diagram is organized by structuring five sub-processes starting from "Negotiation for transport of goods" whose refinement is shown in step 2. At this abstraction level, it is worth noticing that the process continues triggering the "Establishing transport contacts" sub-process when the negotiation process among several participants (consignor, consignee, sea freight forwarder, maritime agent, etc.) reaches an agreement; otherwise, the top-level process ends. In this sub-process, the symbol III asserts that several instances of contracts between parties, for example consignor, sea freight forwarder (sea freight forwarder, maritime agent), (consignor, consignee), can take place contemporarily, reducing the execution time. Again, the control flows toward the next sub-process when an agreement is reached for the stipulation of the contracts, otherwise the control returns back to the negotiation, eventually searching for other partners matching the requirements.

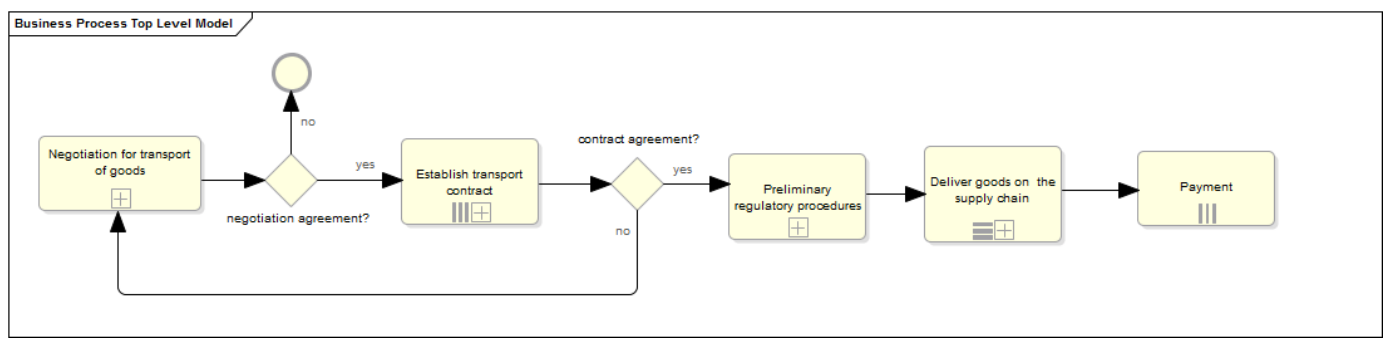

Figure 2: Top level modelling of an export process in international trade

The figure above contains the supply chain outlined by the interviews with the operators of the PCS of Salerno. The sequence of the delivering segment is the following: consignor -> forwarder -> road/railway transporter -> ship transport -> road/railway transporter $->$ consignee. At this abstraction level, each delivering segment (e.g.: consignor->forwarder) is described as an instance of the "Delivering of goods on the supply chain" sub-process. Only when the delivering of goods at one segment ends, the triggering of the next sub-process instance can happen in sequence (symbol 三).

The first step is the "Negotiation for transport of goods", which affects several organizational as well as inter-organizational routines concerning the exporter, sea freight forwarder, maritime agency and the transporter. Information flow starts 
with a request from the exporter to the forwarder for a shipping offer, sent by fax or e-mail. In this phase, the sea freight forwarder interacts both with the carrier as well as the maritime agent to arrange the land and maritime stretch of the shipping. More specifically, in order to formulate its offer, the shipper receives the following information:

- Cargo information provided by the exporter;

- Conditions of maritime transport by the agency;

- Conditions for land transport by the transporter;

- Conditions of storage and handling in the port by the terminal;

- Rules on the functioning of Customs, contained in specific laws.

Each actor carries out the exchange of information described above using traditional methods (fax, e-mail, paper).

In the next step, "Establishing transport contract", actors use the same information of the previous phase. Taking into account that this step only occurs if the previous one ("Negotiation for transport of goods") is successful, the actors involved are the exporter and the sea freight forwarder, who conclude a contract of shipment, which will lead to subsequent inter-organizational routines.

The third step regards the "Preliminary regulatory procedures". The sea freight forwarder usually manages this phase before the transferral of goods occurs, involving the transporter, maritime agency, terminal and Customs. The main inter-organizational routines characterising this stage concern:

- The export declaration, required by Customs;

- The confirmation of booking for the load; and

- The cargo manifest.

The sea freight forwarder presents the export declaration as a confirmation of the ownership of the goods, at the time of export. The export declaration starts the administrative procedure for export, also having a fiscal relevance concerning both the payment of Customs duties and the control function on exported goods. This declaration has to be submitted in electronic format through the AIDA system, by manually entering the data. It contains information regarding the owner, origin, provenance and destination port, identification, quantity, 
description and value of the goods. It is worth noting that the maritime agency we interviewed, manually enters the data concerning both bills of lading and cargo manifests into its own information system (shared with a shipping company); however, this information system is not able to share the same data directly with the AIDA system.

The maritime agency, after receiving a request by fax or e-mail from the forwarder, confirms a booking number for the load on behalf of the maritime shipping company, which, if necessary, allows the containers to be available. The booking number is communicated (by fax or e-mail) to the Terminal, which prepares the space, the resources and services necessary for the reception, the handling and the storage of containers. In addition, based on the booking received, the terminal prepares the load-sheet by manually entering the data into management software.

The maritime agency prepares the cargo manifest, which summarizes all the bills of loading relating to the goods carried by the ship. It uses specific international software for managing the cargo manifests. The cargo manifest must be submitted to the Customs.

Once the necessary preliminary permits are acquired, the delivering of goods on the supply chain is enacted. The fourth step, "Delivering of goods on the supply chain", consists of several routines. The actors involved are the same as in the previous phase. The transporter collects the goods from the exporter and takes them to the port and the booking document and documents relating to the goods are shown in paper form. In the case of containerized cargo, after receiving the booking number, the carrier withdraws the empty container before going to the place of loading the container. The terminal stocks merchandise in a special area of the yard waiting for the inspections. The supervisory authorities inspect the cargo and issue an authorization for the shipment of the goods. After the inspection, the maritime agency prepares the bill of loading on behalf of the shipping company and updates the cargo manifest. Based on the storage plan, the terminal prepares the loading plan for the goods on board the ship, which is performed by specialized staff. Once loading operations are concluded, the captain of the ship asks permission from the harbour master to leave the port and 
informs the destination port of the estimated day of arrival. The supervisory authorities and the harbour master issue paper format permits.

The final sub-process concerns the Payment, which has been conceived as a set of parallel payment instances (consignor, consignee), (consignor, forwarder), etc., accordingly to subscribed contracts.

The schematic analysis of the AS-IS scenario concerning export trade leads us to the following considerations:

- Information circulates between the interested operators through traditional means, such as e-mail, fax or paper documents;

- In the execution of the described routines, different actors are obliged continuously to an expensive manual processing of data (writing of documents, fax and e-mail, entering data in the various online platforms, etc.), with high costs as well as high risks of errors;

- The information system of an actor of the PCS is not able to communicate directly with those of the other involved (private and public) actors;

- The lack of coordination between local control authorities lengthens the time of the controls necessary to authorize the goods.

The operators we interviewed recognize a GAP in comparison with the best practices and what is required by the European legislation. They reported that the problems highlighted as well as the connected high costs increased the export time, having negative consequences on the competitiveness of the port as well as on the efficiency of exporting firms. As such, they acknowledged the need to optimize information flows concerning the goods and the transferral of cargos, through the introduction of a few simple rules which would allow them to easily share information, avoiding the re-typing of the same data: as a relevant example, most of the information could be easily shared through the FAL forms which are prepared in accordance with international rules for the clearance of ships in maritime transport (IMO 2011). However, they were concerned about the difficulties of sharing information because they tend to protect their own data for competitive reasons, and also because they invested resources in implementing their own routines and information system, so they are reluctant to the implementation of a new information system. 


\subsection{To Be Analysis}

The second step describes the TO BE analysis through a refinement of the toplevel sub-processes. The elaboration of the model was based on the information obtained during the AS-IS phase. However, it is operated in the TO-BE phase because the analysis conducted does not take into account the logical flow of trading, its aim being the introduction of a new information system that represents the flow of communication in a unified way. This mode of representation, through the sharing of common data, is able to create a system that can facilitate the coordination between various decision makers.

Generally, a single application of this step is enough to grasp the semantic process at an adequate level. However, it can be recursively applied refining further sub-processes if they appear in the definition of the top-level subprocesses. It is worthwhile to observe that BPMN provides different ways to represent process models according to the point of view highlighted by the analyst. Since we are interested in the communication flow among stakeholders, we refer to a BPMN collaboration diagram that shows the information flow during the sub-process negotiation (see Figure 3).

In the negotiation process, the sea freight forwarder receives a request for quotation from the exporter that contains information about the goods to be shipped. Consequently, he activates a routine that includes a request for information to the transporter and maritime agency. The routines implemented by the shipper end with the submission of an offer that contains all the acquired information. The transporter receives a request for an offer from the forwarder and makes it in accordance with the requirements set and its own internal conditions. The routines end with the formulation of an offer that contains the carriage conditions. The maritime agency receives a request for information from the consignor and provides information about the condition of the sea freight. The routines end with the transmission of information to the consignor. In addition, the consignor consults the charges of the terminal in order to know the port operation costs.

The core of the information exchanged between the actors in the negotiation process consists of the following data: 
- Personal details of the owner of the goods;

- Place of origin, ports of provenance and destination of the goods;

- Number and type of packages;

- Full description of the goods (quality, quantity, trade name);

- Value of the goods.

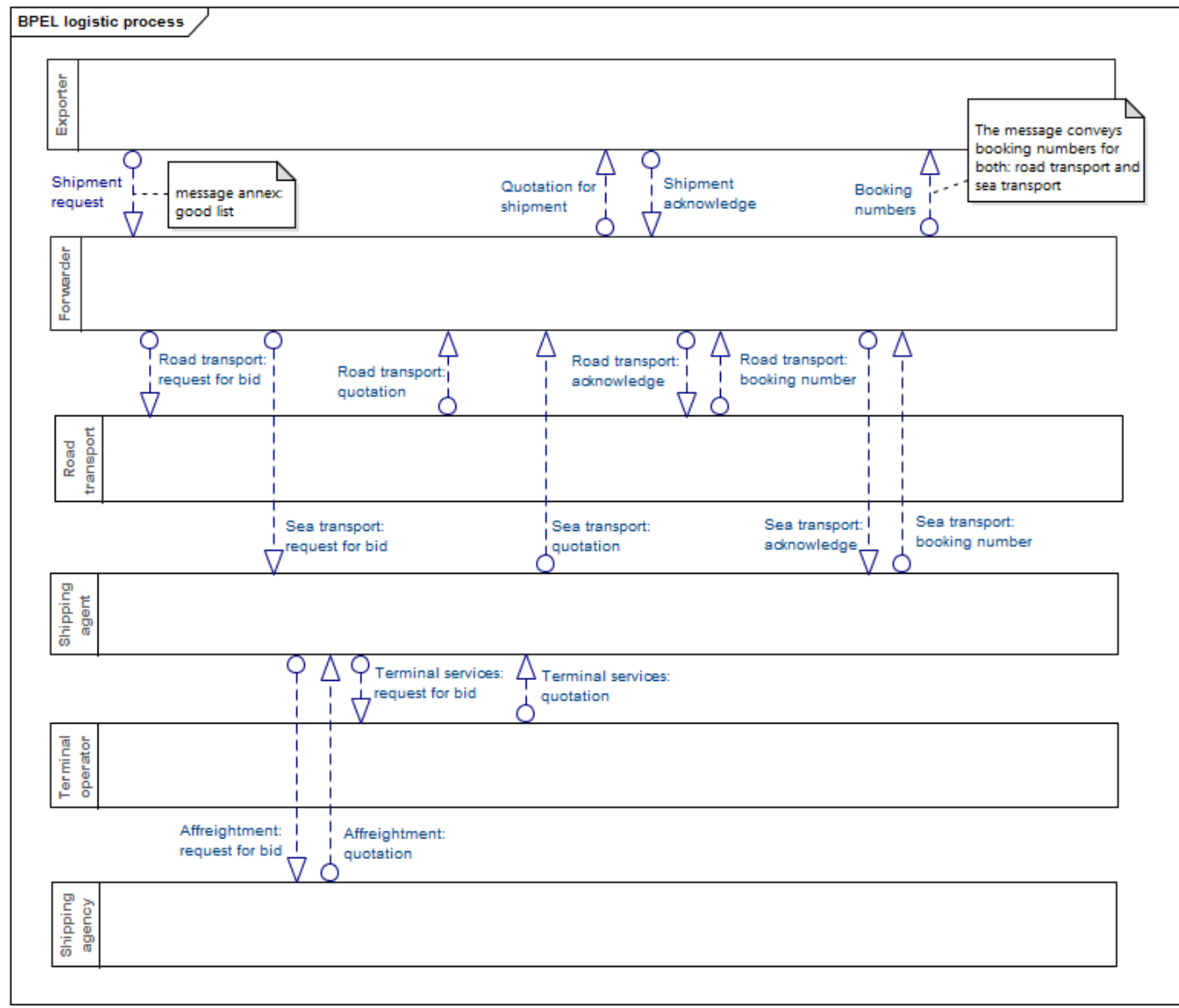

Figure 3: The negotiation process for the transport of goods

This information is included in commercial documents related to the negotiation and is mentioned in both the authorization and organizational documents related to the load.

Best practices and European norms aim to eliminate, as far as possible, the paper documents, often in multiple copies, carried around the port. Shipping lines, maritime agents, sea freight forwarders, brokers, Customs, other port authorities, 
transport operators and the ports/terminal operators rely on information from each other to carry out their functions effectively. The analysis showed that activity in each sector has an impact on the others. If the information could be exchanged between them in an accurate and rapid way, there would be the potential for the whole operation to improve its efficiency, implying a faster transferral of goods.

The XML structuring of freight documents is an important part of the TO-BE analysis that will also be used in the Service/System implementation (see Figure 1). To work properly, the step "Analysis of exchanged documents" provides the identification of common data that are exchanged along the supply chain. As a possible specification of common data, the following XSD (XML schema definition) of a freight that codes the data relaying to the transferral of goods from the consignor to the consignee through a sequence of segments is to be observed:

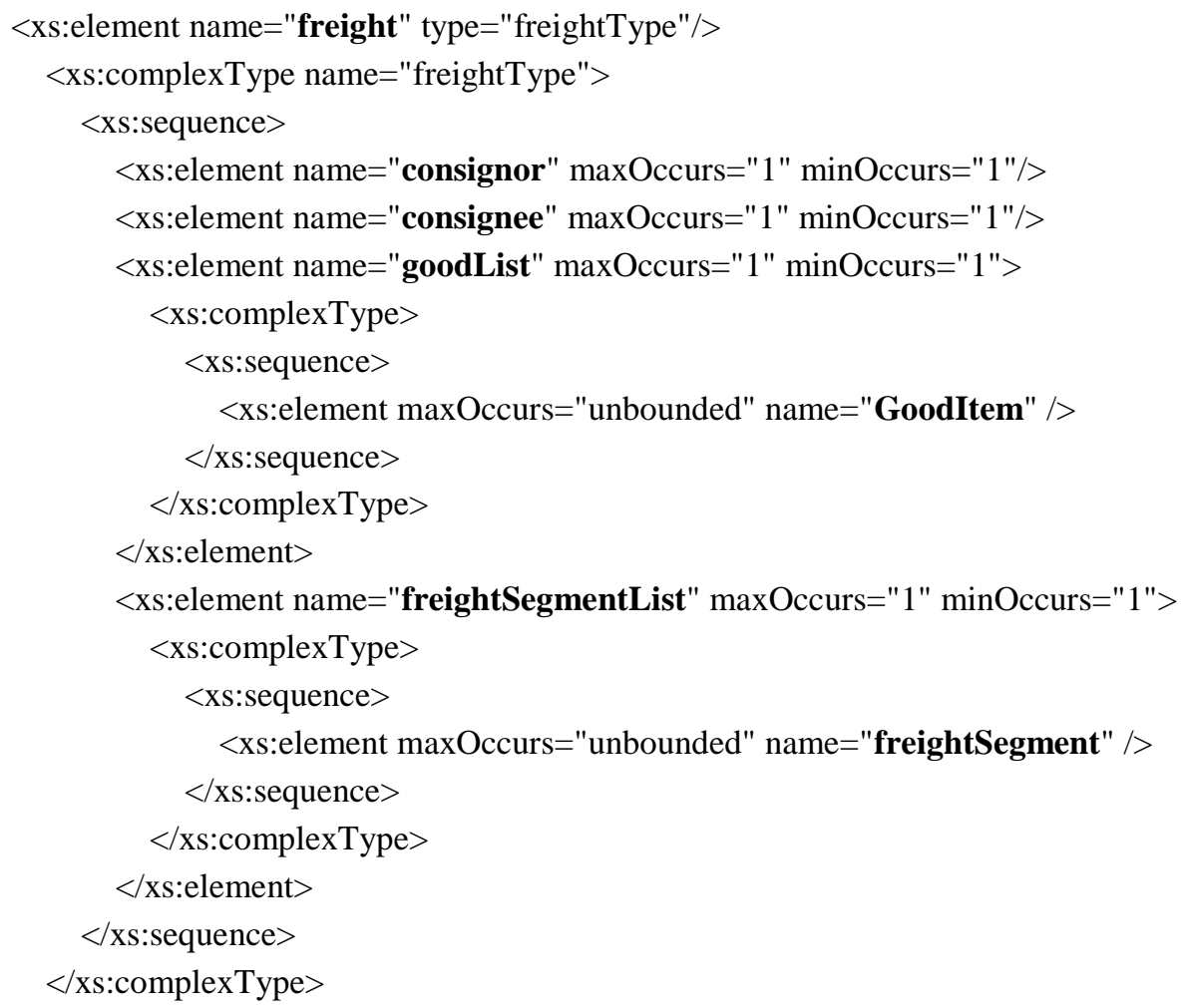

The specification describes that a freight covering the whole supply chain identifies one consignor (the subject that managed the freight), one consignee (the final destination of the goods), a goods list where each good is described by 
name, gross weight, package number, volume, etc. Each element of the XSD shown above is a complex data type. For example, the element "freightSegmentList" is a list of freight segments, with each one further qualified as follows:

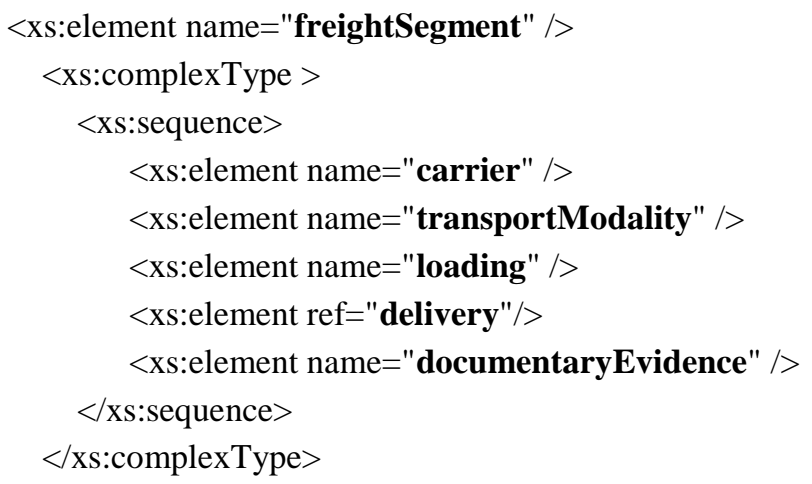

In turn, this fragment of the code is composed of complex data types. The top down specification ends when, as shown in the following code for the data type $<$ delivery>, all the complex data types are qualified in terms of simple data types:

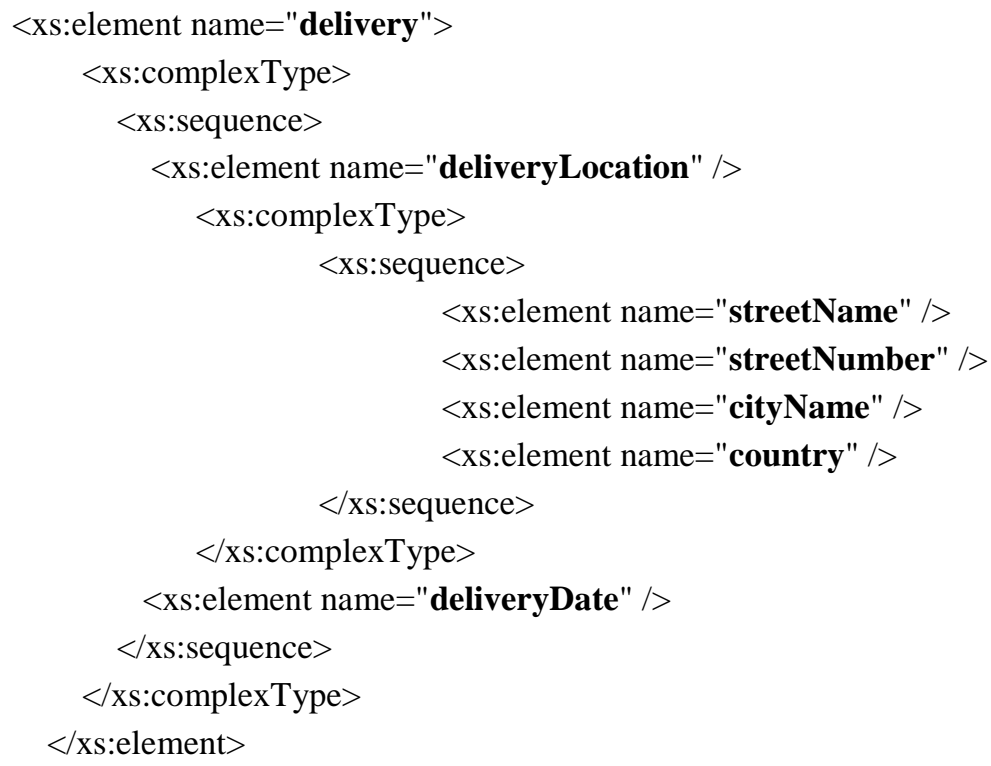

For the purposes of the TO-BE analysis, the data type "documentaryEvidence" is relevant. It must be interpreted as a set of documents, whose structure can also be specified in XSD, that are typically required by several types of stakeholders such as the authorities, the contractors, other actors 
involved in the freight. This set of documents accompanies the main freight document whose structure has been outlined by the XSD shown above. It should be noted that this structure takes into consideration the "whole picture" because all the parties, potentially involved along the supply chain, can benefit from the horizontal relationships that can be developed around XML freight documents that verify the XSD structure.

What we can learn from the analysis is that since the companies' information systems cannot communicate directly with each other and with the various on-line services provided by the institutions, the port operators fail to establish a perfect coordination amongst themselves. The implementation of a system for sharing information automatically and in real time is a key element of coordination through which to fill the GAP in terms of both reducing the bureaucracy time and improving the efficiency in goods handling.

The proposed model contributes to reducing the GAP identified through the AS-IS and the TO-BE analysis. In fact, it creates a core of information that can be shared with a standard format among all the operators in the supply chain. It facilitates the resolution of the following issues:

- Digitalization of the information;

- Multiple manual processing of data;

- Sharing information with individual company information systems;

- Coordination between stakeholders in the supply chain and control institutions;

- Guarantee of data integrity, real time update of data and easy integration with existing (and future) systems.

Since the various players in the supply chain insist on using their own information systems (legacy systems), the defined model has the goal of creating a core of standardized data that acts within the workflow that implements the BPMN models identified in the TO-BE phase interfacing with legacy systems. The model assumes that most PCS components and ICT services exist or will be developed, so it aims to rapidly integrate and support changing business processes (Asbjørnslett et al., 2012). 
The synchronization and coordination between the various actors in the supply chain is performed by feeding the legacy systems with a common data structure represented by the XSD shown above, contacting them during the execution of the workflow. In turn, the legacy systems feed back context information (e.g. execution times of certain activities), enriching the original core and improving the efficiency of the entire supply chain. The individuation of common data exchanged along the supply chain acquired by the described model aims to achieve a more rapid sharing of information, reducing processing time and improving the overall efficiency of the supply chain. This was a necessity requested by the interviewed operators; for example, the CEO of the maritime agency ("Michele Autuori s.r.l.") reports that: "In an integrated sector such as maritime transport, the efficiency of the global supply chain is negatively affected by the time and efficiency of its 'weakest link', so any bottleneck does not allow for the provision of a reliable and efficient transport service".

\section{THE SMART TUNNEL PROJECT}

The Smart Tunnel Project aims to develop a modular technological platform, which will sustain the chain of port logistics and road transport of goods, mainly in the urban area, through the integration of IT technologies and innovative communication systems. In this vein, it would facilitate the transition from the AS-IS to the TO-BE scenario, as well as the transition to a new generation information system (the so-called second generation PCS), having a positive impact in terms of environmental sustainability.

The Smart Tunnel project is designed to support:

- Smart Port Regionalization processes: development and testing of a modular system aimed at improving the integration of maritime transport in the global supply chain, maximizing its safety and efficiency;

- Smart Urban Freight Transport processes: development and testing of a modular system, aimed at improving the integration in the urban transport of goods.

Figure 4 shows an illustration of the general model of the Smart Tunnel project, which focuses on the information flow that takes place during the enactment of logistic processes and outlines our own contribution to the 
development of the Smart Tunnel project. Starting from the process models and the XSD structures presented in the previous section, a subsystem charged to support the coordination and the collaboration along the supply chain has been developed to provide import/export services to several stakeholders. At the current phase of the project, a prototype is in operation enabling the stakeholders: "forwarders, road transporters, shipping agents, terminal operators, shipping companies" to increase the performance of administrative processes through sharing data/information, process coordination and role collaboration.

In particular, a specialized module allows the shipping agent or the shipping company to compile the FAL forms (from FAL_1 to FAL_7) necessary for the clearance of ships in maritime transport (cf. IMO 2011). Several benefits have been introduced; for example, the data concerning the transferal of goods can be captured by the module that must input the IMO cargo declaration (IMO FAL form 2) retrieving common data previously inserted in the Smart Tunnel platform by other organizations during the "Negotiation step", as described in the previous sections. These data can then be completed with the data required for the maritime transport and redirected to the PMIS and AIDA systems for the required authorizations from the Coastguard and the Customs respectively. Another aspect concerns the reduced amount of data typing and errors that could cause costly routines to remediate. For example, analyzing the FAL modules, it is evident that registry data and other data of a ship are the same; the input of these data is only required for the first compiled FAL form and then automatically rewritten in all the remaining FAL forms. Currently, a validation phase is in progress aimed at evaluating if the potential benefits are confirmed during the client acceptance test. Two demonstration sessions have been carried out at the shipping company involved in the Smart Tunnel project that will use the software platform when it is completed. The first impression is encouraging since the technical staff of the shipping company gave positive feedback on the validity of our prototype, requesting two ulterior improvements. The first one is the provision of digital signatures for the maritime transport and clearance documents; the second one is the design and creation of a system that integrates workflow and document capabilities in order to manage, from an administrative point of view, the traffic of ships belonging to their merchant fleet. 


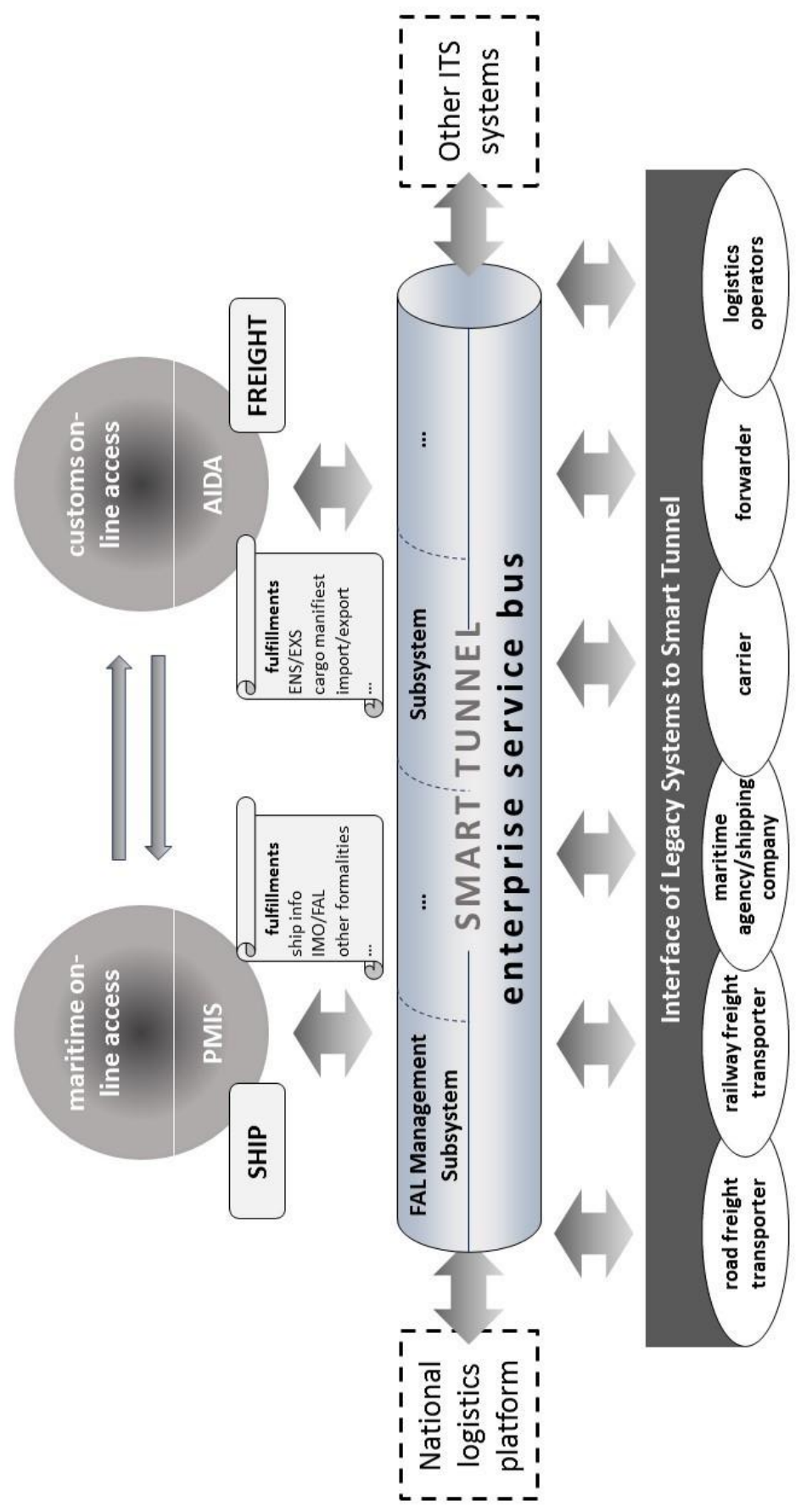

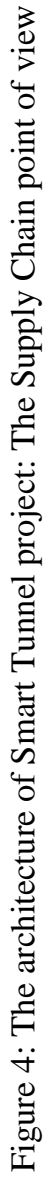




\section{CONCLUSIONS AND FUTURE RESEARCH}

The analysis of the PCS of Salerno in the light of the Smart Tunnel project has highlighted the importance of going beyond a myopic vision based on the adoption of the viewpoint of each actor, without taking into account the relationships between them. Our study differs from relevant prior research in that it proposes a methodological approach based on a microeconomic level of analysis, focusing on both the organizational routines of each partner as well as the inter-organizational routines, which characterise the relationships between them. Bearing in mind that a standardized communication platform is the principal constituent of a PCS, the basic idea of this study is that an in depth understanding of port logistic processes, investigated taking into account the viewpoint of each stakeholder, could be the right path to follow in order to improve their efficiency.

Accordingly, the model and the prototype we proposed in the previous sections aim to improve inter-organizational routines introducing a software component, integrated in the Smart Tunnel platform, which is appropriate for the transmission of easily understood messages at low cost via Internet (Moonen and Srour, 2008, p. 50). This software component is based on both:

a) The web services orchestration language BPEL, and

b) The XML representation of exchanged documents among the actors of a supply chain.

The basic idea of the PCS's concept is the need to standardize messages that actors have to exchange with each other, avoiding as far as possible the re-typing of data. The first generation of the PCS pursued this fundamental objective through a central information platform essentially based on bilateral applications. Our model on one hand follows the trend to move to a second generation of PCS, based on more flexible platform modular middleware, while on the other it aims to improve the efficiency of the global supply chain as well as the efficiency of each actor.

Along this line, the operators of the PCS of Salerno as well as the partners of the Smart Tunnel project on one hand are aware of the presence of determined obstacles (such as the difficulty of combining conflicting objectives of different 
actors and the high level of competition between them); on the other hand, they acknowledge the crucial importance of the innovative idea, inclining towards its acceptance (i.e. they are in the second stage of the Thompson's model). In other words, they recognize that the quality of the whole supply chain fully depends on both the quality and the timeliness of the data available in the platform, of which they seem to appreciate the ability to provide them with information exchange services.

The findings emerging from the first steps of the platform's implementation are highly encouraging on the grounds that the architecture of the model does not aim to replace the information system of each actor: according to Asbjørnslett et al. (2012), our model works towards the replacement of the old interorganizational routines based on tedious tasks with new routines, in order to improve their knowledge of the logistic processes as well as to facilitate the exchange of documents and information.

Future developments of this research will focus on the costs of these logistics processes, through a simulation of different scenario. More specifically, building on the basic idea underlying the model we proposed - to adopt an holistic approach in planning both inventory and transportation processes in order to minimize their costs - we will develop a time-driven activity based costing approach (Somapa et al., 2011).

\section{REFERENCES}

ALLEN, D.; COLLIGAN, D.; FINNIE, A.; KERN, T. (2000): “Trust, power and interorganizational information systems: the case of the electronic trading system transLease", Information Systems Journal, vol. 10, n. 1: 21-40. http://dx.doi.org/10.1046/j.1365-2575.2000.00078.x

ANTONELLI, C. (1994): "Localized technological change and the evolution of standards as economic institutions", Information Economics and Policy, vol. 6, n. 3/4: 195-216. http://dx.doi.org/10.1016/0167-6245(94)90002-7

ASBJØRNSLETT, B.E.; LINDSTAD, H.; PEDERSEN, J.T. (2012): “Information Technology in maritime logistics management: a case-based approach from CoA 
to SLA”. In Song D.W.; Panayides P. M.; Eds. Maritime logistics. Contemporary issues, Emerald: 133-153.

BAGCHI, P.K.; PAIK, S.K. (2001): "The role of public-private partnership in port information systems development”, International Journal of Public Sector Management, vol. 14, n. 6: 482-499. http://dx.doi.org/10.1108/EUM00000000059 65

BARON, M.L.; MATHIEU, H. (2013): "PCS interoperability in Europe: a market for PCS operators?”, The International Journal of Logistics Management, vol. 24, n. 1: 117-129. http://dx.doi.org/10.1108/IJLM-05-2013-0058

BECKER, M.C. (2004): "Organizational routines: a review of the literature", Industrial and Corporate Change, vol. 13, n. 4: 643-677. http://dx.doi.org/10.10 93/icc/dth026

BROOK, O. (1993): “What's It All About?”, Council of Logistics Management.

BUNDUCHI, R.; SMART, A.U. (2010): "Process innovation costs in supply chain networks: a synthesis", International Journal of Management Reviews, vol. 12, n. 4: 365-383. http://dx.doi.org/10.1111/j.1468-2370.2009.00269.x

BURNS, J.; SCAPENS, R.W. (2000): “Conceptualizing management accounting change: an institutional framework", Management Accounting Research, vol. 11, n. 1: 3-25. http://dx.doi.org/10.1006/mare.1999.0119

CHWELOS, P.; BENSABAT, I.; DEXTER, A.S. (2001): "Research report: empirical test of an EDI adoption model", Information Systems Research, vol. 12, n. 3: 304-321. http://dx.doi.org/10.1287/isre.12.3.304.9708

DACIN, M.T.; GOODSTEIN, J.; SCOTT, R.W. (2002): "Institutional Theory and Institutional Change: Introduction to the Special Research Forum", Academy of Management Journal, vol. 45, n. 1: 45-56. http://dx.doi.org/10.5465/AMJ.2002.6 283388

DAMANPOUR, F.; SCHNEIDER, M. (2006): "Phases of the adoption of innovation in organizations: effects of environment, organization and top managers", British Journal of Management, vol. 17, n. 3: pp. 215-236. http://dx.doi.org/10.1111/j.1467-8551.2006.00498.x 
DILLARD, J.F.; RIGSBY J.T.; GOODMAN, C. (2004): "The Making and Remaking of Organization Context: Duality and the Institutionalization Process", Accounting, Auditing \& Accountability Journal, vol. 17, n. 4: 506-542. http://dx.doi.org/10.1108/09513570410554542

EDMONDSON, A. C.; MCMANUS, S. E. (2007): "Methodological fit in organizational field research", Academy of Management Review, vol. 32, n. 4: 1246-1264. http://dx.doi.org/10.5465/AMR.2007.26586086

EISENHARDT, K.M.; GRAEBNER, M.E (2007): "Theory Building From Cases: Opportunities And Challenges", Academy of Management Journal, vol. 50, n. 1: 25-32. http://dx.doi.org/10.5465/AMJ.2007.24160888

EPCSA, European Port Community Systems Association (2011): White Paper, The role of Port Community Systems in the development of the Single Window. http://goo.gl/La6yMH, accessed: 1 August 2013.

GUPTA, A.; KAUFFMAN, R.J.; WU, A.P. (2008): "Do firm R\&D investments drive decisions to join? On the value of standard-setting organizations in the consumer electronics industry", Paper presented at the 41st HICSS Conference, Hawaii, 7-10 January. http://goo.gl/vjFfE4 ; accessed: 16 May 2014.

HART, P.J.; SAUNDERS, C.S. (1998): "Emerging electronic partnerships: antecedents and dimensions of EDI use from the supplier's perspective", Journal of Management Information Systems, vol. 14, n. 4: 87-112.

IACOVOU, C.L.; BENBASAT, I.; DEXTER, A.S. (1995): "Electronic data interchange and small organizations: adoption and impact of technology", MIS Quarterly, vol. 19, n. 4: 465-485. http://dx.doi.org/10.2307/249629

IMO (2011): Guidelines for setting up a single window system in maritime transport, FAL. Circ. 36 Nov 2011. http://goo.gl/Z6kBxW accessed: 2 April 2014.

IRANI, Z.; LOVE, P.E.D. (2000/2001): "The propagation of technology management taxonomies for evaluating investments in information systems". Journal of Management Information Systems, vol. 17, n. 3: 161-177. 
JIMENEZ-MARTINEZ, J.; POLO-REDONDO, Y. (2004): "The influence of EDI adoption over its perceived benefits", Technovation, vol. 24, n. 1: 73-79. http://dx.doi.org/10.1016/S0166-4972(02)00047-0

KWON, T.H.; ZMUD, R.W. (1987): "Unifying the fragmented models of information systems implementation”, In Borland, R.J.; Hirschheim, R.A.; Eds. Critical Issues in Information Systems Research. John Wiley: 227-251.

LONG, A. (2009): "Port community system", World Customs Journal, vol. 3, n. 1: 63-67.

LOUNSBURY, M. (2007): “A Tale of Two Cities: Competing Logics and Practice Variation in the Professionalizing of Mutual Funds", Academy of Management Journal, vol. 50, n. 2: 289-307. http://dx.doi.org/10.5465/AMJ.200 7.24634436

MOONEN, H.; SROUR, J. (2008): "Port Community System Architectures". In van Baalen, P.; Zuidwijk, R.; van Nune, J., Port Inter-Organizational information systems. Capabilities to service global supply chains; Foundations and Trends ${ }^{\circledR}$ in Technology, Information and Operations Management, 2, (2-3): 45-56.

NAKAYAMA, M. (2000): "E-commerce and firm bargaining power shift in grocery marketing channels: a case of wholesalers' structured document exchanges", Journal of Information Technology, vol. 15, n. 3: 195-210. http://dx.doi.org/10.1080/02683960050153165

NELSON, R.R.; WINTER, S.G. (1982): An evolutionary Theory of Economic Change, Harvard University Press.

PIERCE, J.L.; DELBECQ, A.L. (1977): "Organization structure, individual attitudes and innovation”, Academy of Management Review, vol. 2, n. 1: 27-37.

RODON, J.; RAMIS-PUJOL, J. (2006): "Exploring the intricacies of integration with a port community system", BLED 2006 Proceedings, Paper 9. http://aisel.aisnet.org/bled2006/9; accessed: 16 May 2014.

SCAPENS, R.W. (1994): "Never mind the gap: toward an institutional perspective on management accounting practice", Management Accounting Research, vol. 5, n. 3/4: 301-321. http://dx.doi.org/10.1006/mare.1994.1019 
SCOTT, W.R. (2001): Institutions and Organizations, Thousand Oaks: Sage.

SEO, M.G.; CREED, W.E.D. (2002): "Institutional Contradictions, Praxis, and Institutional Change: A Dialectical Perspective", Academy of Management Review, vol. 27, n. 2: 222-247. . http://dx.doi.org/10.5465/AMR.2002.6588004

SOMAPA, S.; COOLS, M.; DULLAERT, W. (2011): “The development of time driven activity-based costing models: A case study in a road transport and logistics company". In Notteboom, T.; Eds. Current issue in shipping, ports and logistics; Uitgeverij UPA, University Press Antwerp: 431-445.

SWANSON, E.B. (1994): "Information systems innovation among organizations", Management Science, vol. 40, n. 9: 1069-1092. http://dx.doi.org/10.1287/mnsc.40.9.1069

THOMPSON, V. (1965): "Bureaucracy and innovation", Administrative Science Quarterly, vol. 10, n. 1: 1-20. http://dx.doi.org/10.2307/2391646

UN/CEFACT (2005): Recommendation and Guidelines on establishing a Single Window to enhance the efficient exchange of information between trade and government, Recommendation n. 33. http://goo.gl/xo8U9i, accessed 2 April 2014.

UN/CEFACT, working draft: Case Studies on Implementing a Single Window to enhance the efficient exchange of information between trade and government http://goo.gl/XJXIjG accessed 2 April 2014.

VAN BAALEN, P.; ZUIDWIJK, R. (2008): “Introduction”. In van Baalen, P.; Zuidwijk, R.; van Nune, J., Port Inter-Organizational information systems. Capabilities to service global supply chains; Foundations and Trends ${ }^{\circledR}$ in Technology, Information and Operations Management, vol. 2, n. 2-3: 1-20.

VAN BAALEN, P.; ZUIDWIJK, R.; VAN NUNEN, J. (2008): "Port interorganizational information systems: capabilities to service global chains", Foundations and Trends ${ }^{\circledR}$ in Technology, Information and Operations Management, vol. 2, n. 2/3: 81-241. http://dx.doi.org/10.1561/0200000008

VAN OOSTERHOUT, M., (2008): “Organizations and Flows in the network". In van Baalen, P.; Zuidwijk, R.; van Nune, J.; Port Inter-Organizational information systems. Capabilities to service global supply chains, Foundations and Trends ${ }^{\circledR}$ in Technology, Information and Operations Management, vol. 2, n. 2-3: 93-102. 
VAN OOSTERHOUT, M.; SROUR, J.; VEENSTRA, A.; MOONEN, H.; ZUIDWIJK, R. (2008): “Cases”, in van Baalen, P.; Zuidwijk, R.; van Nune, J., Port Inter-Organizational information systems. Capabilities to service global supply chains, Foundations and Trends ${ }^{\circledR}$ in Technology, Information and Operations Management, vol. 2, n. 2-3: 103-146.

WCO (2009): Data Model, World Customs Organization.. http://www.wcoomd.org/ WEBER, M.M.; KANTAMNENI, S.P. (2002): "POS and EDI in retailing: an examination of underlying benefits and barriers", Supply Chain Management. An international journal, vol. 7, n. 5: 311-317.

YIN, R. K. (1994): Case study research: Design and methods (2nd ed.). Newbury Park, CA: Sage.

ZHU, K.; KRAEMER, K.L.; GURBAXANI, V.; XU, S. (2006): “Migration to open-standard interorganizational systems: network effects, switching costs, and path dependency", MIS Quarterly, 30, August (special issue), 515-539.

ZMUD, R.W. (1982): "Diffusion of modern software practices: influence of centralization and formalization", Management Science, vol. 28, n. 12: 14211431. http://dx.doi.org/10.1287/mnsc.28.12.1421 